\title{
Introduction: Special Section on Pressure Gain Combustion
}

Frank K. Lu, Robert Miller, Mohamed Razi Nalim and Kenneth H. Yu

This is the author's final manuscript of the article published in final edited form as:

Lu, F. K., Miller, R., Nalim, M. R., \& Yu, K. H. (2017). Introduction: Special Section on Pressure Gain Combustion. Journal of Propulsion and Power, 33(1), 16-16. https://doi.org/10.2514/1.B36585 
Pressure increase in a mechanically confined deflagrative combustion process is commonplace, with the internal combustion engine being a widespread example. Such devices have weight and other limitations related to the use of positive displacement for the purpose of compression and expansion in addition to pressure-gain combustion. Thus, significant benefits are possible from the development of devices that focus primarily on pressure-gain combustion, allowing much higher throughput and more complete work or kinetic energy extraction to occur in a downstream turbine or nozzle. This includes the use of non-steady gas dynamics and detonations to achieve thermodynamic benefits that are at least equivalent to constant-volume combustion.

The attributes of pressure-gain combustion have been studied for over a century and have resulted in proposals to develop practical engines. The past few decades have seen a pickup in interest in pressure gain combustion due to their potential advantages. A particular genre is pulsed detonation engines [1], a technology that has seen interest spreading rapidly worldwide with a number of centers of excellence. Various potential rocket and airbreathing applications were proposed. Research and development spanned thermodynamic analysis and systems integration. Developments in numerical and experimental techniques were advanced as well. Much effort was spent in understanding fundamental physical processes, the key of which is to ensure reliable onset of detonation in a short distance and repeatability over an extended period of time. These efforts have led to sufficient understanding for the first flight of a PDE on January 31, 2008. * A different detonation-based engine, known as the rotating detonation engine (RDE) which can be traced to the late 1950s, received renewed interest due to its numerous advantages compared to the PDE []].

Predating this recent period of interest in detonation engines was interest in other forms of combustion engines that do not fit well into conventional, deflagration-based categories. These were characterized by unsteadiness and more pertinently by "pressure gain" [ $\underline{3}]$. A working definition of pressure gain combustion (PGC) is that it "is a periodic process, in a fixed volume, whereby gas expansion by heat release is constrained, causing a rise in stagnation pressure and allowing work extraction by expansion to the initial pressure". I One such device that utilizes non-steady gas dynamics and deflagration in a temporarily confined space is the internalcombustion wave rotor [4]. The wave rotor uses the principles of pressure-wave machines that have been developed over the past century. The pulsed jet is another

Due to the rapid and broad interest in pressure gain combustion, the AIAA Pressure Gain Combustion Program Committee (PGC PC) was established in 2013 and it "seeks to advance the investigation, development, and application, of pressure gain combustion technologies for improving propulsion and power generation systems and achieving new mission capabilities".t

One of the outcomes of the PGC PC is this special section. With adequate fundamental understanding of combustion and flow processes achieved over the past two decades, it is now pertinent to gather together papers that describe the state-of-the-art in experimental and modeling techniques. This special section represents the work from different laboratories and covering a wide range of topics, whose common theme is on developing technologies that will bring pressure gain combustion into practice. These papers also point the way toward future challenges. We trust that they will be invaluable to those who are already researching in PGC and also to those who need to be brought up to speed. 
* Data available online at:

http://www.nationalmuseum.af.mil/Visit/MuseumExhibits/FactSheets/Display/tabid/509/Article/ 195765/scaled-composites-long-ez-borealis.aspx

$\dagger$ Data available online at https://info.aiaa.org/tac/pc/PGCPC/Resources/Resources.aspx

+ Data available online at https://info.aiaa.org/tac/pc/PGCPC/default.aspx 


\section{Authors}

Rrank K. Lu, University of Texas at Arlington.

Robert Miller, Cambridge University.

Mohamed Razi Nalim. Indiana University Purdue University Indianapolis

Kenneth H. Yu, University of Maryland 


\section{References}

1. Kailasanath, K., "Recent Developments in the Research on Pulse Detonation Engines," AIAA Journal, Vol. 41, No. 2, 2003, pp. 145-159. doi:10.2514/2.1933

2. Lu, F. K., and Braun, E. M., "Rotating Detonation Wave Propulsion: Experimental Challenges, Modeling, and Engine Concepts," Journal of Propulsion and Power, Vol. 30, No. 5, 2014, pp. 1125-1142. doi:10.2514/1.B34802

3. Kentfield, J. A. C., Rehman, M., and Marzouk, E. S., "A Simple Pressure-Gain Combustor for Gas Turbines," Journal of Engineering for Power, Vol. 99, No. 2, 1977, pp. 153-158. doi:10.1115/1.3446261

4. Akbari, P., and Nalim, M. R., "Review of Recent Developments in Wave Rotor Combustion Technology," Journal of Propulsion and Power, Vol. 25, No. 4, 2009, pp. 833-844.

doi:10.2514/1.34081 